\title{
Pre-hospital delay of patients with ST-elevation myocardial infarction in Mexico City
}

\author{
Retraso prehospitalario en pacientes con infarto agudo de miocardio en la Ciudad de \\ México
}

\author{
Diego Araiza-Garaygordobil1* , Héctor González-Pachecoํ, Carlos Sierra-Fernández", \\ Francisco Azar-Manzur', José L. Briseño-De la Cruz', Marco A. Martínez-Ríos², \\ Carlos Martínez-Sánchez ${ }^{1}$, and Alexandra Arias-Mendoza ${ }^{1}$ \\ ${ }^{1}$ Coronary Unit; ${ }^{2}$ Administrative Office. Instituto Nacional de Cardiología Ignacio Chávez, Mexico City, Mexico
}

Mr. Editor,

In Mexico, $47.4 \%$ of patients with acute ST-segment elevation myocardial infarction (STEMI) do not receive reperfusion therapy ${ }^{1}$. Although multiple factors contribute to this phenomenon ${ }^{2}$, the delay until reperfusion (attributable to the patient or to the health system) might constitute an important barrier to timely reperfusion. The purpose of this work is to assess pre-hospital delay time (onset to door) in Mexican patients with acute STEMI.

We carried out a descriptive, retrospective study of the onset-to-door time in patients older than 18 years with a final diagnosis of STEMI, presenting to a cardiovascular care center in Mexico City between January 2013 and May 2016. Reperfused (fibrinolysis or angioplasty initiation before the first $12 \mathrm{~h}$ ) and non-reperfused patients were included in the study. The study patients attended directly or were referred to the study center to receive fibrinolysis, primary angioplasty or to complete a pharmacoinvasive strategy; the study center is the only one that offers $24 / 7$ primary angioplasty services for patients without health insurance in Mexico City.
This work focused on onset-to-door time, which contemplates the interval from the onset of symptoms to the arrival at the door of a hospital with capacity for angioplasty or fibrinolysis ${ }^{3}$. Simultaneously, the time from symptom onset to first medical contact (time to first medical contact) was analyzed. The information was obtained from the electronic medical record: if no data were available, the case was excluded from the study. For statistical analysis, categorical variables were described with percentages and continuous variables with non-normal distribution, by means of medians and interquartile ranges (IQR).

A total of 1494 patients with acute STEMI were included in the sample. Patients were mostly males (83.7\%), with systemic arterial hypertension (47.0\%), and had a history of tobacco use $(33.2 \%)$ and a history of type 2 diabetes mellitus (38.8\%). The reperfusion rate was $62.7 \%$, with 451 subjects $(30.1 \%)$ receiving fibrinolysis and 487 (32.6\%) primary angioplasty.

Information on pre-hospital delay time was found in $91.4 \%(n=1365)$ of medical records. Median onset-todoor time was 648 (IQR: 371-748) min. Median time to first medical contact was $138 \mathrm{~min}$ (IQR: 87-152). Among

\section{Correspondence:}

*Diego Araiza-Garaygordobil

Juan Badiano, 1

Col. Belisario Domínguez Seccion XVI, Del. Tlalpan

Date of reception: 13-09-2017

Date of acceptance: 28-08-2018

DOI: $10.24875 /$ ACME.M19000043
Available online: $30-10-2019$ Arch Cardiol Mex (Eng). 2019;89(2):174-176 www.archivoscardiologia.com 


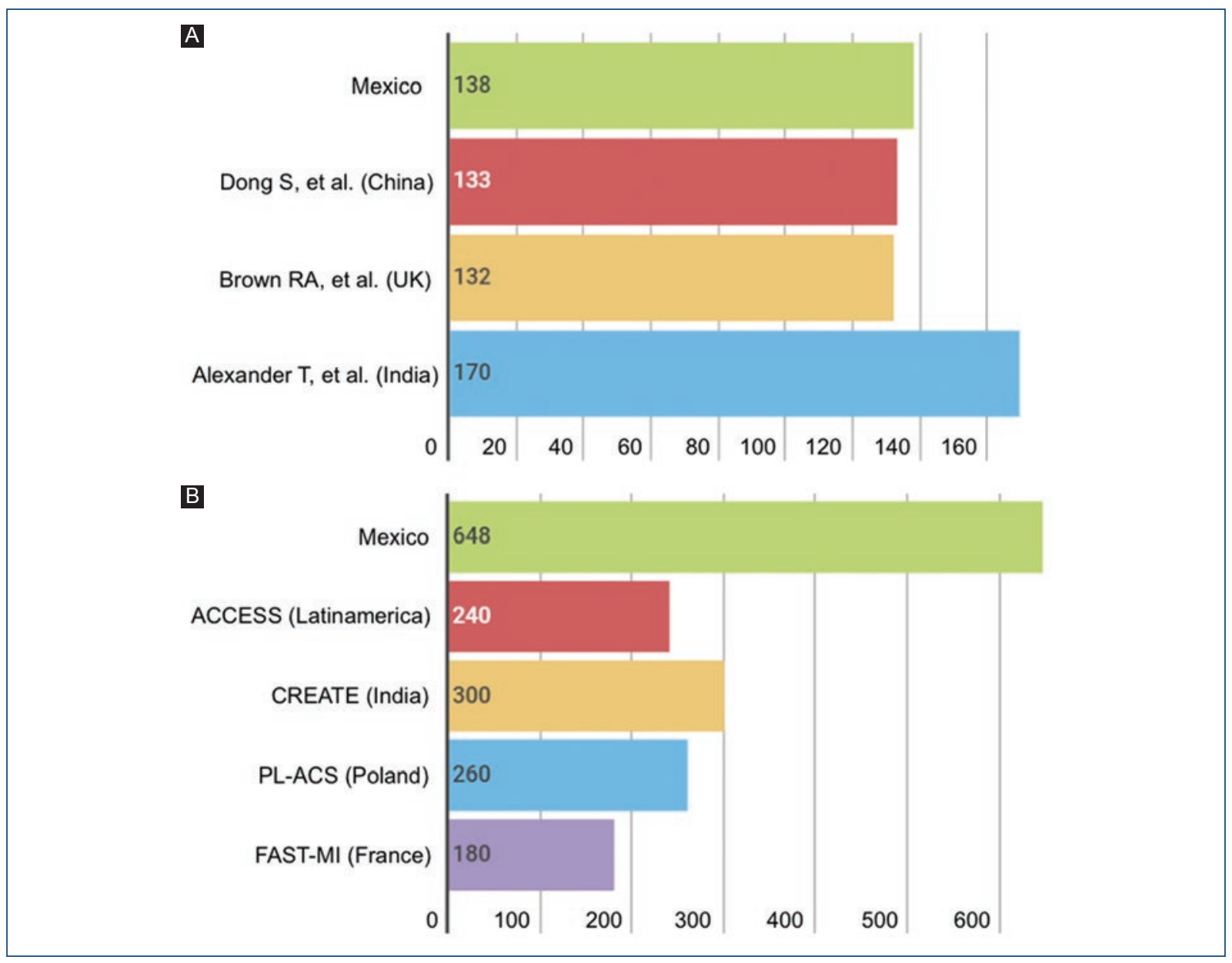

Figure 1. A: comparison of time to first medical contact in patients with acute ST-segment elevation myocardial infarction (STEMI) in Mexico and other countries (median in minutes); B: comparison of onset-to-door time in patients with acute STEMI in Mexico and other countries (median in minutes).

ACCESS: ACute Coronary Events - a multinational Survey of current management Strategies; CREATE: Treatment and Outcomes of Acute Coronary Syndromes in India; FAST MI: French Registry on Acute ST-Elevation Myocardial Infarction; PL ACS: Polish Registry of Acute Coronary Syndromes.

the patients who did not receive reperfusion (510; $37.3 \%), 26.8 \%$ (137) had a first medical contact within the first $12 \mathrm{~h}$ after the onset of symptoms.

Total ischemia time is a factor associated with outcomes such as mortality, infarction final size, and heart failure ${ }^{4}$. Several factors can influence on total ischemic time, including geographic, cultural, social, and health system-related variables. Pre-hospital delay (onset-todoor time) can be divided in two: patient-associated (time to first medical contact) and system-associated delay (first medical contact to door). Patient-associated delay depends on social and geographical factors such as accessibility to health services and cultural factors on the perception and interpretation of their symptoms. When comparing the results of our study with other registries, time to first medical contact in Mexico is similar to that observed in other countries (Fig. 1A). Registries from China, the United Kingdom, and India have reported times to first medical contact of 132-170 min $^{5,6}$ in comparison with 138 min observed in our study.

It is the system-related delay in Mexico that is concerning. A median of 510 min $(8.5 \mathrm{~h})$ was identified in this work, resulting in an onset-to-door time of $648 \mathrm{~min}$. Registries of acute coronary syndromes in countries such as Poland Polish Registry of Acute Coronary Syndromes (PL-ACS) ${ }^{7}$ and France (FAST$\mathrm{MI})^{8}$ have reported onset-to-door times of 180 260 min. In developing countries, the ACCESS ${ }^{9}$ (Latin America, Africa, and the Middle East) and CREATE $^{10}$ (India) registries reported 240-300 min. Our study shows an onset-to-door time that doubles 
the time reported in the CREATE registry and at least triples the results of the French registry (Fig. 1B). The causes behind this phenomenon can be multiple: Mexico City's metropolitan area geographical extension, traffic conditions, health system fragmentation in different providers, deficiencies in diagnostic and referral capacity, etc.

This study did not delve into door-needle time or door-balloon time, which are time subintervals that, although widely known, indicate the quality of care of a hospital and not the functionality of a health system. Limitations of this work include an inherent selection bias: the study center is a national referral hospital. It is possible for patients with more serious and complex pathology to have been transferred to the study center. Information on pre-hospital delay was obtained through interrogation directed at the patient and/or relative and at the referral hospital doctor at the time of admission and might be subject to recall bias.

This work represents only a snapshot of a single center and its geographical surroundings, and a population-based assessment would be required to understand a complex situation such as the dynamics of cardiac infarction management. However, this study emphasizes the importance of assessing this delay in infarction care systems in other geographical regions and establishing measures to reduce the medical system delay time in the care of acute myocardial infarction in Mexico.

\section{Funding}

There was no funding for the performance of this work.

\section{Conflicts of interest}

The authors report that there are no conflicts of interest relevant to the performance of this work.

\section{Ethical disclosures}

Protection of people and animals. The authors declare that no experiments were carried out on humans or animals for this research.

Confidentiality of data. The authors declare that they have followed the protocols of their work center on the publication of patient data.

Right to privacy and informed consent. The authors declare that no patient data appear in this article.

\section{References}

1. Martinez-Sánchez C, Borrayo G, Carrillo J, Juarez U, Quintanilla J, Jerjes-Sánchez C. Clinical management and hospital outcomes of acute coronary syndrome patients in Mexico: The Third National Registry of Acute Coronary Syndromes (RENASICA III). Arch Cardiol Mex. 2016; 36:221-324

2. Martínez-Sánchez C, Arias-Mendoza A, González-Pacheco H, AraizaGaraygordobil D, Marroquín-Donday LA, Padilla-lbarra J, et al. Reperfusion therapy of myocardial infarction in Mexico: A challenge for modern cardiology. Arch Cardiol Mex. 2017;87:144-50.

3. Song JX, Zhu L, Lee CY, Ren H, Cao CF, Chen H. Total ischemic time and outcomes for patients with ST-elevation myocardial infarction: does time of admission make a difference? J Geriatr Cardiol. 2016; 13:658-64.

4. Denktas AE, Anderson HV, McCarthy J, Smalling RW. Total ischemic time: the correct focus of attention for optimal ST-segment elevation myocardial infarction care. JACC Cardiovasc Interv. 2011;4:599-604.

5. Dong S, Chu Y, Zhang H, Wang Y, Yang X, Yang L. et al. Reperfusion times of ST-Segment elevation myocardial infarction in hospitals. Pak J Med Sci. 2014;30:1367-71.

6. Alexander T, Mullasari AS, Joseph G, Kannan K, Veerasekar G, Victor SM, et al. A System of care for patients with ST-segment elevation myocardial infarction in India: The Tamil Nadu-ST-Segment Elevation Myocardial Infarction Program. JAMA Cardiol. 2017; 2:498-505.

7. Poloński L, Gasior M, Gierlotka M, Kalarus Z, Cieśliński A, Dubiel JS, et al. Polish Registry of Acute Coronary Syndromes (PL-ACS). Characteristics, treatments and outcomes of patients with acute coronary syndromes in Poland. Kardiol Pol. 2007:65:861-72.

8. Danchin N, Coste P, Ferrières J, Steg PG, Cottin Y, Blanchard D, et al; FAST-MI Investigators. Comparison of thrombolysis followed by broad use of percutaneous coronary intervention with primary percutaneous coronary intervention for ST-segment-elevation acute myocardial infarction: data from the french registry on acute ST-elevation myocardial infarction (FAST-MI). Circulation. 2008; 118:268-76.

9. Bazzino O, Monaco R, Mario B, Sergio C, Valeria CM, Sergio E, et al. ACCESS Investigators. Management of acute coronary syndromes in developing countries: acute coronary events-a multinational survey of current management strategies. Am Heart J. 2011;162:852-9.

10. Xavier D, Pais P, Devereaux PJ, Xie C, Prabhakaran D, Reddy KS, et al; CREATE registry investigators. Treatment and outcomes of acute coronary syndromes in India (CREATE): a prospective analysis of registry data. Lancet. 2008;371:1435-42. 